\title{
Decisões Estratégicas na Logística do Agronegócio: Compensação de Custos Transporte-Armazenagem para a Soja no Estado do Paraná
}

\author{
Ricardo Silveira Martins \\ Daniele Rebechi \\ Celso A. Prati \\ Honório Conte
}

\begin{abstract}
Resumo
Este estudo objetivou avaliar a viabilidade dos investimentos em armazenagem da soja como decisão estratégica de logística. O princípio teórico é o de compensação de custos logísticos, tendo por base que a decisão estratégica empresarial pauta-se pelo somatório dos custos logísticos, visando a identificar sua área de custos mínimos totais das operações. Nessa visão, é possível tomar uma decisão acertada de operação, mesmo contando com uma ou mais atividades de logística fora de seu ponto mínimo. Nos custos de armazenagem, foi considerado o valor anual equivalente (VAE), tomado como remuneração do capital; o valor presente líquido (VPL) foi utilizado como indicador da viabilidade do investimento realizado. Foi possível comprovar a eficiência dos investimentos em estruturas de armazenagem, tanto em nível de grandes quantidades, quanto para o caso de uma propriedade estudada. Com maiores possibilidades de não vender a safra no momento de custos de transportes elevados, o custo logístico anual é menor, sendo tanto menor à medida que mais esta capacidade se aproximar da unidade. Assim, o investimento é viabilizado pela remuneração de seus custos operacionais e pelas economias de fretes. Ficou destacado o custo de transporte como direcionador dos custos logísticos setoriais.
\end{abstract}

Palavras-chave: logística agroindustrial; estratégias logísticas; agronegócio da soja.

\begin{abstract}
The objective of this article was to analyses the viability of the investments in soybean stocking as a strategic decision in logistics. The theorical principle used is the compensation of logistics costs, so that the entrepreneurial strategic is based in sum of the logistics costs, intending to identify the minimum total costs area of the operations. In this approach, it is possible to take an accurate decision about the operations, even if one or more than one of the logistics activities is out of its minimum point of cost. In storage costs, it was took in count the equivalent annual value (EAV), as the capital payment; The net present value (NPV) was used as viability of the investiment indicator. In that way, it was possible to confirm the efficiency of the investments into storage structures, either in a level of numerous quantities of grain or in the case of the studied farm. The annual logistics expenditures are lower when there is a larger possibility of not selling the harvest when the transportation costs are high, and they keep on decreasing as these structures come near the commercialization units. That means that the remuneration of the operational costs and the savings in transportation make the investments viable. This work also emphasizes the transportation costs as a determinant of the sectorial expenditures in logistics.
\end{abstract}

Key words: agribusiness logistics; logistics strategy; soybean agribusiness. 


\section{INTRODUÇÃO}

O conhecimento dos custos de qualquer atividade econômica tende a proporcionar uma série de possibilidades de criação de vantagens competitivas. A gestão de custos é uma oportunidade clara da utilização de ferramenta de apoio na tomada de decisões, uma vez que para a correta identificação de prioridades ou medidas gerenciais, visando à maximização dos resultados, as empresas necessitam, cada vez mais, de informações precisas, que reflitam a realidade dos custos de seus produtos.

Neste contexto, o gerenciamento dos custos da atividade é essencial para a competitividade empresarial, pois possibilita a correta mensuração do resultado, além da própria sobrevivência em mercado cada vez mais competitivo. Para o setor, os efeitos podem ser visualizados na seguinte linha de raciocínio: com remuneração insuficiente, o setor não se moderniza, presta serviço de baixa qualidade, implicando, para o agregado da economia, a formação de estoques acima dos níveis aceitáveis de segurança e perdas, dentre outras ineficiências, que acabam repercutindo como agregação de custos na economia.

Pimenta (1998) chama a atenção para os desafios da gestão dos custos na logística. Um deles é conseguir gerenciar a relação entre custo e nível de serviço (trade-off). O maior obstáculo é que cada vez mais os clientes estão exigindo melhores níveis de serviço; mas, ao mesmo tempo, não estão dispostos a pagar mais por isso. Assim, imputa-se à logística a tarefa de agregar valor ao produto por meio do serviço por ela oferecido. Entre estas exigências por serviço, o autor destaca: redução do prazo de entrega; maior disponibilidade de produtos; entrega com hora determinada; maior cumprimento dos prazos de entrega; maior facilidade de colocação do pedido.

Por outro lado, a gestão dos custos deve ser vista também como insumo nas decisões estratégicas dos negócios. Dentre estas, decisões de localização, número de armazéns, centros de distribuição, fonte de suprimentos e decisões sobre o transporte podem ser enumeradas. Por exemplo, uma melhora do setor de transporte pode contribuir para o aumento da eficiência econômica do País, com redução dos custos com estoques. Segundo a Confederação Nacional dos Transportes (2002), cerca de R 118 bilhões de excesso de estoque são mantidos pelas empresas brasileiras ao longo das cadeias produtivas como forma de se proteger das ineficiências do transporte, conseqüência de atrasos, acidentes e roubos de carga. 
Estas estratégias também estarão sujeitas a influências do ambiente do negócio. A adoção de modernas técnicas de administração empresarial, com redução sensível nos estoques (Just in Time), que reforça as decisões estratégicas da logística e da eficiência das operações para as empresas, terão importante papel na construção da estratégia da empresa.

Algumas dificuldades no custeio das atividades logísticas estão ligadas à alta proporção de custos indiretos e à grande segmentação de produtos e serviços. Por outro lado, muito freqüentemente, estas dificuldades têm a adesão da problemática do gerenciamento de custos dos parceiros numa cadeia de suprimentos. Os transportadores estarão interessados em operar em rotas mais rentáveis, por exemplo. Já os operadores logísticos estarão disputando cargas de maior praticidade no manuseio.

No caso do agronegócio, estas dificuldades têm algumas especificidades. Longe de uma perspectiva industrial, de produção programada e estoques com a possibilidade de longa vida de prateleira, a produção agroindustrial deve gerenciar incertezas e sazonalidades, como os períodos de safra e entressafra e perdas ocasionadas pela deterioração ou vencimento da vida útil do produto. Além do mais, a produção é pulverizada regionalmente e em termos de unidades de produção, e ainda majoritariamente comercializada via mercado spot, sendo que este se apresenta altamente volátil no decorrer dos anos, implicando significativas oscilações nos preços praticados e formados nos mercados internacionais.

Por exemplo, a soja, um ícone do agronegócio no país, tem atividades gerenciais bastante complexas. Este agronegócio movimenta volume físico e financeiro elevado, exigindo ampla visão empresarial por parte dos produtores, fornecedores de insumos, processadores da matéria prima e negociantes, de forma a manter e estender as vantagens competitivas de produção. Nas estratégias, muitas vezes opta-se pela comercialização da safra diretamente das propriedades para os portos, mesmo sem a programação de navios, ou empresas de beneficiamento, sem atividades de armazenagem que poderiam gerar vantagens na comercialização.

Isto porque, muitas vezes, a evolução de todos os elos da cadeia agroindustrial não acontece no mesmo ritmo. Por exemplo, apesar do crescimento da produção de grãos verificado nos últimos anos, a capacidade estática dos armazéns cadastrados na Companhia Nacional de Abastecimento (CONAB), não vem apresentando evolução significativa. No Paraná, registrava-se uma capacidade estática de 17.711 mil t em 1990, regredindo a 17.693 mil t em 2000 (PARANÁ, 2001), ou seja, a infra-estrutura de armazenagem no campo ainda é insuficiente para atender à demanda da safra.

O preço pago ao produtor, além de determinante da cotação internacional, sofre forte influência dos custos de armazenagem e frete. Nos Estados Unidos, os 
produtores maximizam a lucratividade, conjugando a armazenagem na fazenda com o transporte da safra via ferrovia-hidrovia. Já no Brasil só os grandes produtores dispõem de estrutura de armazenagem na fazenda, enquanto os pequenos e médios se defrontam com duas opções: ou fazem a venda logo após a colheita ou utilizam armazéns de terceiros, arcando, em ambos os casos, com despesas de limpeza, secagem e, no segundo caso, armazenagem.

Considerando-se que, durante a safra, há aumento significativo na demanda por caminhões, devido à necessidade de comercialização imediata da produção, elevam-se também os preços de fretes; no entanto, durante a safra, o preço da commodity sofre redução. Uma vez que o produto esteja estocado, poderia haver avaliação do melhor momento para comercializar a produção. Assim, a pergunta a que esta pesquisa pretende responder é a seguinte: Diante desses fatores, não seria viável financeiramente o investimento em estruturas de armazenagem nos traders regionais, principalmente cooperativas, e mesmo nas propriedades?

Este estudo analisou a viabilidade dos investimentos em infra-estrutura de armazenagem na busca de reduzir custos logísticos totais, com interesse específico em:

a) Avaliar o histórico dos fretes da soja no Estado do Paraná, com vistas à identificação de sazonalidade.

b) Identificar estruturas de armazenagem e respectivos custos de investimento e operacionais, tanto para grandes compradores quanto para propriedades.

c) Avaliar, na perspectiva dos custos logísticos totais, a estratégia de investimentos na estrutura de armazenagem.

Na próxima seção, são delineados os princípios norteadores de elaboração de estratégias logísticas, considerando-se as especificidades dos transportes e da armazenagem, bem como são apresentadas algumas particularidades do agronegócio da soja que limitam ou potenciam algumas estratégias. Na seção seguinte, são apresentados os conceitos formulações, definição de equações e variáveis e demais considerações meteorológicas e dos valores. Os resultados são analisados em seção posterior, discutindo-se a pertinência e viabilidade econômico-financeira dos investimentos em armazéns, enquanto na seção subseqüente se apresentam algumas considerações e conclusões.

\section{Gestão Estratégica da Logística e as Especificidades do Agronegócio da Soja}

O objetivo da integração da cadeia de abastecimento é a minimização do custo 
total logístico, que é a soma dos custos de produção, estoque, armazenagem, transporte e distribuição. Assim, a gestão logística busca, por meio da gestão financeira, diminuir custos e aumentar a produtividade dos ativos, isto é, aumentar o giro de estoques, reduzir os ciclos de suprimento e diminuir o ciclo de pedidos.

As decisões sobre estratégias logísticas referem-se à definição do arranjo entre os diferentes componentes logísticos: estrutura de instalações; processamento de pedidos; manutenção de informação; transporte; manutenção de estoques; e armazenagem e manuseio. Estas decisões são baseadas em análise de balanceamento entre diferentes alternativas (trade-off), para busca de menor custo total.

Alguns princípios fundamentais que auxiliam o tratamento integrado das atividades logísticas nas empresas merecem ser destacados.

- Compensação de custos. Este conceito reconhece que há comportamentos conflitantes, se os componentes logísticos forem considerados individualmente. Para a minimização dos custos deve-se fazer um balanceamento entre outros componentes logísticos. Como exemplo, Ballou (1993) utilizou os custos relacionados ao número de depósitos existentes num sistema de distribuição, conforme Figura 1.

\section{Figura 1: Compensação de Custos para Determinação do Total de Depósitos em um Sistema de Distribuição}

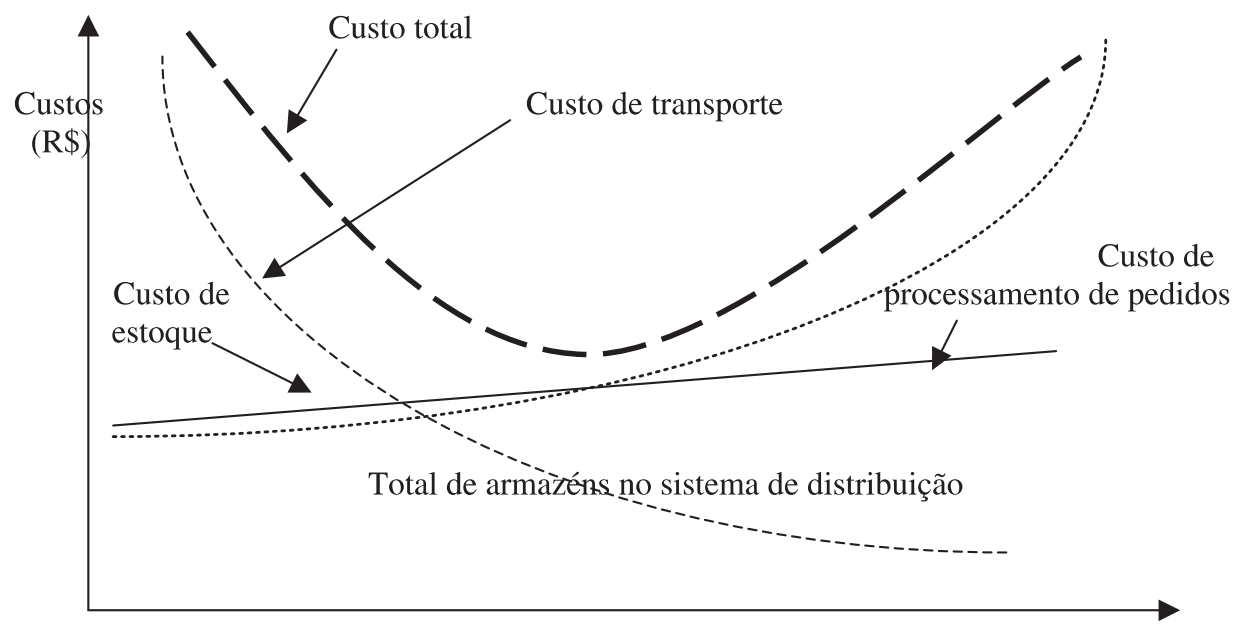

Fonte: Ballou (1993).

A Figura 1 mostra que, quanto maior os números de depósitos, menores são os custos com transportes, porque os carregamentos podem ser feitos para os depósitos a fretes menores; porém se nota que os custos com estoques aumentam, conforme aumenta o número de depósitos. Isso ocorre porque mais estoque é 
necessário para manter o mesmo nível de disponibilidade do que quando há menor número de depósitos; os custos com processamento de pedidos também aumentam, porque os depósitos servem como pontos de processamento de pedidos.

. Conceito de custo total. Os conceitos de custo total e compensação de custos caminham lado a lado. Conforme mostra a Figura 1, custo total é a soma dos custos de transporte, estoque e processamento de pedidos. Assim, o ponto mínimo da curva de custo total situa o número de armazéns que melhor minimiza custos.

. Conceito de sistema total. Este conceito é uma extensão do conceito de custo total; porém o enfoque do sistema total leva em consideração todos os fatores afetados, de alguma forma, pelos efeitos da decisão tomada, isto é, relaciona-se diretamente com muitas outras áreas funcionais, dentro e fora dos limites legais da empresa.

Assim, uma decisão primária na rede logística pode estar vinculada às decisões sobre transporte e armazenagem, de forma vinculada. A confiabilidade e a agilidade dos transportes poderão implicar menores quantidades armazenadas, por exemplo, numa perspectiva de interação dos custos totais e nível do serviço. As estratégias logísticas serão modeladas, considerando-se os atributos desejados pelo negócio e o que pode ser viabilizado pelas atividades primárias de transporte e armazenagem.

Segundo Bayliss (1996), convencionalmente, os agentes econômicos modelam decisões relativas à utilização dos serviços de transporte em quatro estágios:

a) definição da existência da carga a ser transportada;

b) identificação do destino a ser atendido;

c) seleção do modal de transporte e tipo de veículo a ser utilizado;

d) definição da rota de transporte a ser seguida.

Estrategicamente, porém, as decisões que envolvem o mercado são tomadas constantemente. No curto-prazo, enquanto os embarcadores estão optando por uma política de estoque e estão gerenciando esses estoques, as transportadoras trabalham na determinação das melhores rotas, incorporando atributos como distância, apoio, existência de pedágio, na adequação dos veículos às necessidades da demanda (capacidade e potência). No médio-prazo, as transportadoras passam a se preocupar com o nível do serviço prestado, adequando a frota à demanda, porquanto, neste prazo, é possível o embarcador mudar de prestador de serviço, até mesmo desenvolver canal logístico por outro modal de transporte. No longo-prazo, a insegurança é ainda maior, pois o embarcador pode decidir alterar sua localização geográfica, obrigando o transportador a desenvolver nova rede de transporte. 
Assim, a tomada de decisão envolve algumas peculiaridades. Considerando a ótica da empresa, como parcerias no transporte, redução de base de parceiros, a incorporação da tecnologia da informação, dentre outros fatores, levam Araújo e Martins (2002) a buscar explicações teóricas a partir da Teoria dos Custos de Transação. Esta teoria faz parte do arcabouço da Nova Economia Institucional, que teve no trabalho de COASE (1937) o início da construção de novo paradigma para o estudo das organizações. Sob esta nova visão, Williansom (1989) impulsiona uma vertente mais associada ao estudo da coordenação das firmas integradas verticalmente, a partir do conceito de custo de transação, que é "o custo de administrar o sistema econômico", ou seja, "são os custos de adquirir e processar informações relativas a contratos referentes a eventos futuros que não podem ser previstos com certeza; os custos organizacionais incorridos pelo comportamento ineficiente das partes contratantes e os custos legais na quebra de contratos”.

Alguns fatos do mercado realçam a possível adequação dessa interpretação teórica:

a) O embarcador necessita da garantia de que sua mercadoria será entregue em tempo e perfeitas condições.

b) No mercado de transporte de grãos, observa-se maior ocorrência de comportamentos oportunísticos, pelo que grandes demandantes, com freqüência, preferem manter parte da frota própria.

c) A determinação do frete no mercado depende da análise de custos, incorporando outros atributos, tais como localização geográfica, carga de retorno, valor da carga.

No que diz respeito aos transportes, o mercado de frete rodoviário no Brasil, e em particular o de cargas agrícolas, não sofre nenhum tipo de controle pelo governo, significando que os preços são formados com base na livre negociação entre a oferta e a procura pelo serviço de transporte (CAIXETA-FILHO, 1998).

Caixeta-Filho (2001) afirma que a safra da soja é, sem dúvida, a que mais desestabiliza o mercado de frete, isto é, com a utilização intensa dos serviços de transporte, pois os veículos disponíveis se tornam escassos e os valores de frete se elevam significativamente.

Correa Jr. et al. (2001) destacam algumas variáveis que exercem influência sobre o estabelecimento do frete, que são: distância percorrida; custos operacionais; possibilidade de obtenção de carga de retorno; agilidade dos processos de carga e descarga; sazonalidade da demanda por transporte; especificidade de carga transportada e do veículo utilizado; perdas e avarias; vias utilizadas; volume e valor do pedágio; rigor da fiscalização; prazo de entrega; alguns aspectos geográficos. 
Nesse sentido, pode-se exemplificar alguns desses fatores. A maioria dos trabalhos que abordam a estrutura dos fretes praticados considera a distância como o principal fator de determinação de valores, independentemente do modal utilizado.

Beilock et al. (1996) afirmam também que, de modo geral, estudos que procuram identificar os determinantes dos fretes rodoviários são, primeiramente, dependentes das distâncias e, secundariamente, ajustados por outros fatores. A distância percorrida influi no valor unitário do transporte, ou seja, no frete por tonelada ( R\$/t), implicando a sensibilidade do valor em relação à quilometragem rodada.

Todas as variáveis são levadas em consideração na determinação dos preços de frete; mas o principal mecanismo a ser considerado é a negociação entre os agentes. A demanda de serviços nesse mercado, na maioria dos casos, detém o poder de negociação em face da oferta de serviço de transporte, criando assim um sistema no qual há grande número de empresas disputando um mercado composto por pequeno número de demandantes importantes, situação teórica descrita no conceito de oligopsônio.

Para o caso deste estudo, porém, destaca-se a sazonalidade, porquanto, nos períodos da safra o valor do frete sofre tendência de alta. Por exemplo, no mês de março, pico da safra de verão, o frete se torna mais caro em relação à entressafra no mês de novembro (Tabela 1). Esta prática do mercado sugere que investimentos na capacidade de armazenagem poderiam gerar economias no custo logístico total, possibilitando o transporte fora do período de pico da safra.

\section{Tabela 1: Fretes Rodoviários para Movimentação da Soja em Novembro de 2002 e Março de 2003, Rota Campo Verde (MT) - Santos (SP)}

\begin{tabular}{cccc}
\hline Período & R\$/t. & R\$/t.m & $\begin{array}{c}\% \\
\text { acréscimo } \\
\text { na safra }\end{array}$ \\
\hline Nov/02 & 94,82 & 0,0605 & $\mathbf{4 6 , 4 8}$ \\
Mar/03 & 138,89 & 0,0886 & \\
\hline
\end{tabular}

Fonte: SIFRECA (novembro de 2002 e março de 2003).

Por outro lado, a não ocorrência do transporte nos períodos de safra ocasionará custos de estoque e armazenagem. Pimenta (2000) destaca como custos de armazenagem os que se referem ao acondicionamento dos bens e a sua movimentação, tais como aluguel do armazém, mão-de-obra, depreciação das empilhadeiras etc, enquanto os custos de estoque se referem aos bens, produzidos ou comercializados, propriamente ditos, como o custo financeiro de estoque e o custo de perdas, devido a roubo, obsolescência e avarias. 
Com a tendência de elevação da linha de produtos e da freqüência de entregas, novos atributos vêm sendo requeridos das atividades de armazenagem. Como resultado, novas tecnologias de processo e de informação têm sido incoporadas, sinalizando a importância estratégica da operação destas estruturas.

No caso dos produtos do agronegócio não é diferente. O problema tem a especificidade da relativa rigidez da área de produção, em contraposição a uma constante ocupação de novas fronteiras por parte da população. Particularmente, no caso da armazenagem de produtos de origem agrícola, além dessas características, há que se considerar como estratégica a transparência do mercado do produto e do mercado de fretes, para decidir quando e quanto vender e quando e quanto armazenar e aguardar o melhor momento.

Além do mais, enquanto estratégia, os investimentos em estruturas de armazenagem são prejudicados pelo elevado custo de captação dos recursos, pela volatilidade dos mercados e pelas características do próprio custo. Boa parte dos custos de operação de um armazém é fixa, o que dificulta o gerenciamento eficiente destas operações, colocando sua viabilidade enquanto investimento apenas à medida que esteja bastante transparente para o gestor de que a estrutura terá uso de capacidade bastante significativa e não sazonal.

\section{Logística no Sistema Agroindustrial da Soja}

Segundo Alves (1997), o setor agroindustrial brasileiro vem passando por inúmeras transformações no processo de integração ao mercado. Observa-se crescente preocupação com a qualidade, busca de expansão da linha de produtos com maior valor agregado, adequação das formas organizacionais às necessidades do mercado, globalização, novos hábitos de consumo alimentar, mais rapidez na transmissão de informações. Isso tudo leva a conseqüentes mudanças nas estratégias de produção e distribuição das empresas, em busca de melhoria da capacidade competitiva.

Com relação aos segmentos que compõem o Sistema Agroindustrial (SAG) da Soja, a indústria processadora está atravessando processo intenso de concentração, tanto no estágio de esmagamento/refino, quanto de derivados de óleo, em função das inúmeras fusões e aquisições. Um segmento importante do SAG envolve os chamados originadores. Estes coordenam o suprimento de matérias primas por meio da aquisição, armazenagem e distribuição de matérias primas. Podem ser tradings, cooperativas, corretoras, armazenadores e até empresas de esmagamento.

Tradings são empresas que atuam mais fortemente como commodities, coordenando a transferência física de produtos no mercado nacional e internacional. A medida que participam do processo de aquisição de soja, tornam- 
se concorrentes diretos do segmento industrial. As corretoras atuam mais como prestadoras de serviços à indústria esmagadora e até mesmo tradings na formação de lotes de matéria prima para venda, originários de produtores ou cooperativas. Algumas corretoras tem a função de operar para terceiros em bolsas, viabilizando operações de transferência de riscos. Armazenadores apresentam característica pouco definida no Brasil. O Governo tem atuado de forma intensa na atividade de armazenagem, como por exemplo, por meio de órgãos como a CONAB, porém vem buscando transferir à iniciativa privada essa função.

Apesar dos contextos favoráveis nos mercados internacionais, existem entraves ligados ao suprimento de bens públicos e coletivos: infra-estrutura de transporte, portuária e armazenagem; informações para embasar o processo decisório e estratégico; necessidade de investimentos em $P \& D$, especialmente para a busca de novos produtos derivados da soja.

Quando há boa infra-estrutura de transporte a eficiência do sistema agroindustrial é maior, pois se conseguem menores custos de movimentação interna e externa de produtos, além de tornar possível a produção em novas áreas. A questão da logística dos transportes na agroindústria possui grande importância, pois causa forte impacto na determinação dos preços pagos ao produtor.

Um dos estrangulamentos enfrentados pelo setor é a indisponibilidade de outros modais alternativos ao rodoviário. Segundo Caixeta-Filho (2001), no caso de produtos agrícolas (granéis sólidos), a concentração modal é muito inadequada, sendo o rodoviário responsável por $80 \%$ das cargas, o ferroviário, 8-10\%, e as hidrovias ficam com o restante. Conforme demonstram a Figura 2, a inadequação é comprovada para os casos da movimentação das cargas do complexo soja no Brasil.

\section{Figura 2: Matriz de Transporte para o Complexo Soja no Brasil}

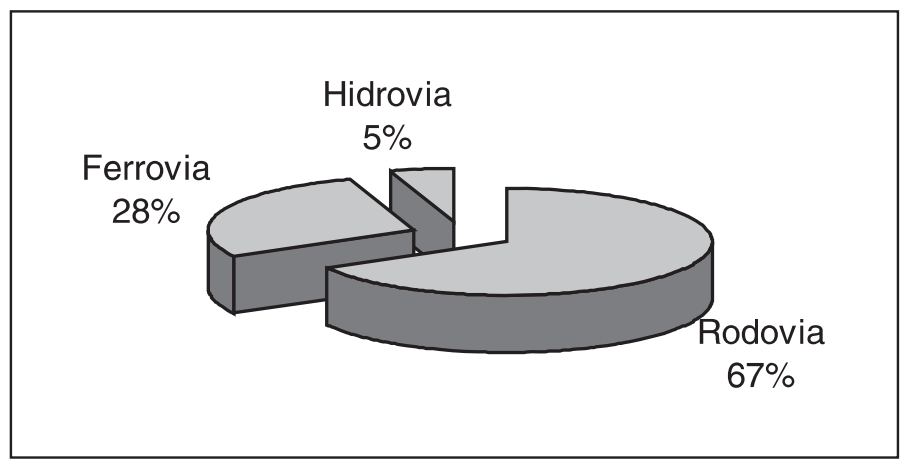

Fonte: Costa et al. (2002). 
De acordo com Soares et al. (1997), a safra da soja, que ocorre entre os meses de março e abril, é a que mais desestabiliza o mercado do frete no Brasil. É o fator que traz maiores impactos sobre o mercado de transporte rodoviário de cargas. Isso é explicado pelo fato de que os produtores realizam a colheita muito rapidamente; hoje isso é acentuado pelo uso de máquinas maiores e mais eficientes; sem ter onde armazenar o produto, buscam comercializá-lo logo após a colheita. As colheitas das safras acontecem geralmente entre os meses de fevereiro a maio para a soja, e de janeiro a junho para o milho. Os agricultores realizaram a quase totalidade das colheitas nesses períodos, salvo algumas pequenas variações. No caso do milho, ocorre também a segunda safra que é colhida entre os meses de julho e setembro.

Na safra de 2001, a intensa demanda por serviços de transporte causou escassez de caminhões, elevando o frete. O aumento no volume da safra de grãos do Paraná fez dobrar o valor do frete pago aos caminhoneiros que transportam os produtos para o Porto de Paranaguá: o preço médio passou de $\mathrm{R} \$ 25,00$ por tonelada, praticado no início do ano, para $\mathrm{R} \$ 50,00$ em meados de março, quando cooperativas agropecuárias e outros exportadores intensificaram a procura de transporte para o escoamento da safra.

Ademais, a lentidão no percurso entre a propriedade agrícola e a indústria, e a maior necessidade de manutenção do caminhão nestes trechos, geralmente não pavimentados, são fatores que também elevam os custos dos fretes.

Além de impactos no mercado de fretes, essa situação provoca o comprometimento da capacidade de armazenagem no interior, fazendo com que o produto destinado à exportação seja encaminhado para o Porto de Paranaguá, mesmo sem programação de embarque nos navios. Tal prática tem ocasionado também o esgotamento da capacidade de armazenagem no porto. Outro aspecto importante é a pressão que as boas condições de comercialização exercem sobre a colheita. Quando o real está desvalorizado em face do dólar, os produtores buscam acelerar os procedimentos de remessa de seus produtos para o porto, para garantir maiores ganhos e liquidez.

Dessa maneira é possível perceber a importância do armazenamento da produção agrícola. Durante a safra o preço das commodities costuma sofrer queda, devido à grande quantidade ofertada, enquanto os fretes, devido à intensa demanda, tendem a ser mais caros; em alguns casos observa-se elevação de até $100 \%$ no seu preço.

O produtor comercializa a produção neste período, porque tem de cobrir seus fluxos de caixa, mas também por não ter infra-estrutura de armazenagem suficiente e adequada. Caso pudesse armazenar pelo menos parte da safra colhida, obteria 
melhores preços na comercialização do grão. Além disso, pagaria menores fretes, já que estes costumam sofrer queda abrupta após a safra da soja e continuam decrescendo lentamente durante o restante do ano, até que se inicie a nova safra.

Complementando a logística associada ao agronegócio da soja, o porto de Paranaguá é o maior exportador de produtos agrícolas e é aquele que tem a maior infra-estrutura para a movimentação de grãos da América Latina, e responsabiliza-se por um terço das exportações de soja e de farelo no Brasil. Segundo Martins et al. (2002), é possível fazer a seguinte caracterização operacional do porto:

“a) A capacidade estática de armazenagem é de 1,13 milhão de t. Porém, na prática, apenas se conseguem operar cerca de 750-800 mil t em razão da necessidade de segregação de produtos por tipo e por origem e da falta de condições estruturais para executar essa separação sem perda de espaço. ...

d) A permanência dos caminhões no pátio está condicionada pela capacidade de recebimento das moegas, pela falta de espaço nos armazéns, pela falta de programação dos operadores, pelo atraso dos navios e pelo não atendimento dos motoristas aos chamados dos terminais.

e) O Porto opera com alta taxa de ocupação dos berços, 67-89\%, superior ao recomendado para níveis mais satisfatórios de operação, segundo a ONU/UNTACD. Além disso, o processo de embarque nos navios está condicionado pelas condições das marés e do tempo (as chuvas interrompem o embarque)”.

\section{Metodologia}

Nesta seção, são apresentados os conceitos de engenharia financeira utilizados, as formulações e respectivas equações que definem os custos logísticos de transporte e de armazenagem, bem como as variáveis, valores e natureza e fonte dos dados utilizados.

\section{Conceitos de Engenharia Financeira}

Um primeiro conceito utilizado no estudo foi o de Taxa Mínima de Atratividade (TMAR). Esta é uma taxa definida para representar a taxa de remuneração do capital utilizada para avaliação das propostas de investimento. De maneira geral, 
o custo de captação de capital no mercado para a empresa torna-se a base para a análise de investimento.

Para a composição dos custos associados ao investimento dos traders em armazéns, foi utilizado o método do Custo Anual Equivalente (CAE). Este método transforma o fundo de caixa de uma alternativa de investimento, num fluxo uniformemente distribuído, utilizando-se uma TMAR, Taxa Mínima de Atratividade. Faz-se isto calculando-se o VPL, Valor Presente Líquido, de cada alternativa em análise; em seguida transforma-se o valor obtido em uma série uniforme para o prazo de cada alternativa.

Para cálculo do VPL soma-se algebricamente, no instante atual, todas as variações de caixa esperadas para um período, descontadas a uma determinada taxa de juros chamada de taxa de desconto.

Segundo Hummel (1995), a formula abaixo descreve o cálculo do Valor Presente Liquido (VPL):

$$
V P L=\sum_{J=1}^{N} \frac{X_{J}}{(1+i)^{j}}
$$

sendo:

$\mathrm{X}_{\mathrm{j}}=$ Valor da parcela

$\mathrm{i}=$ Taxa de Juros

n = Número de parcelas

Como referência para a viabilidade dos investimentos nas propriedades, foi utilizado o método da Taxa Interna de Retorno, TIR. Por definição, é a taxa de juros que torna uma série de recebimentos e desembolsos equivalentes na data presente. No caso do valor da TIR ser maior que a TMAR, tem-se um indicador de aprovação do investimento.

Na situação de incorporação do capital investido no custo de armazenagem foi utilizado o método do Valor Anual Equivalente (VAE). No caso do presente estudo, este é o caso dos custos, transformando a ótica para o Custo Anual Equivalente (CAE).

Neste método transforma-se o fundo de caixa da alternativa de investimento em análise num fluxo uniformemente distribuído, utilizando-se uma TMAR. Fazse isto calculando-se o VPL; em seguida transforma-se o valor obtido em uma série uniforme para o prazo de cada alternativa. 


\section{Custos Logísticos}

Inicialmente, foram coletadas informações históricas sobre os preços dos fretes no Oeste do Paraná através de dados disponibilizados pelo SIFRECA - Sistemas de Informações de Fretes para Cargas Agrícolas (SIFRECA, vários números). Outros elementos necessários ao estudo são informações dos custos de investimento em armazenagem e dos custos operacionais, que foram disponibilizados por empresas cerealistas.

Foi realizada a análise de estratégias de investimento do capital privado em infra-estrutura de armazenagem para instalação e funcionamento na região Oeste do Paraná. Para isso, utilizaram-se os conceitos de compensação de custos e de custo total, princípios fundamentais dentro da abordagem de gestão logística e decisão estratégica.

Conceitualmente, a abordagem do custo total, ou também custo logístico, foi entendida como a soma dos custos de transporte e armazenagem. Logo, se fez necessário caracterizar como é formado cada um destes custos e como foram calculados.

Para cálculo dos custos de transporte, foi necessário avaliar o histórico de fretes da Região Oeste do Paraná, com a finalidade de identificar sazonalidade e, com isso, a diferença nos preços dos fretes praticados na safra e na entressafra. Como este estudo pretende analisar a viabilidade da estratégia do investimento em armazenagem na Região Oeste do Paraná, foram coletados dados sobre preços de fretes ao longo dos 12 meses dos anos 2000, 2001 e 2002, tendo como rotas Cascavel-Paranaguá, Assis Chateaubriand-Paranaguá e PalotinaParanaguá.

Aos preços de fretes obtidos para estas rotas foi aplicado o Índice Geral de Preços (IGP) de novembro de 2002. Desta maneira foi possível obter a média dos fretes unitários (em $\mathrm{R} \$ / \mathrm{t}$ ) praticados durante os meses de safra, que engloba, principalmente, os meses de março e abril, e a média dos fretes durante os meses de entressafra, englobando principalmente junho a novembro. Assim, o frete da safra refere-se às médias dos meses da safra, no período indicado, e das rotas. Para o frete da entressafra, o mesmo princípio prevaleceu.

O custo de transporte foi calculado pelo uso do frete na safra e na entressafra, e as respectivas quantidades, da seguinte maneira:

$$
\text { CUSTO DE TRANSPORTE }(\mathrm{CT})=\left(\mathrm{F}_{\mathrm{s}} \times \mathrm{Q}_{\mathrm{s}}\right)+\left(\mathrm{F}_{\mathrm{e}} \times \mathrm{Q}_{\mathrm{e}}\right)
$$

sendo: 
$\mathrm{F}_{\mathrm{s}}=$ Preço unitário médio do frete praticado durante a safra (em $\mathrm{R} \$ / \mathrm{t}$ ).

$\mathrm{F}_{\mathrm{e}}=$ Preço unitário médio do frete praticado durante a entressafra (em $\mathrm{R} \$ / \mathrm{t}$ ).

$\mathrm{Q}_{\mathrm{s}}=$ Quantidade de produto transportada durante a safra.

$\mathrm{Q}_{\mathrm{e}}=$ Quantidade de produto transportada durante a entressafra.

Para cálculo do custo de armazenagem foi preciso definir a capacidade estática dos armazéns em que se deseja investir.

Assim, foi definido como padrão uma estrutura de armazenamento com capacidade para 42.000 toneladas, cujo custo do investimento é de $\mathrm{R} \$ 4$ milhões, e o custo operacional é de $\mathrm{R} \$ 3,30 / t$ ano, segundo dados fornecidos pela Cooperativa COMIGO, de Rio Verde (GO).

Com estes dados, foi possível calcular o Custo Anual Equivalente (CAE) deste armazém. O valor obtido para o CAE, a uma Taxa Mínima de Atratividade (TMAR) de 3\% ao ano, proporcionou o valor de R \$335.066,00/ano.

Portanto, pode-se calcular os custos de armazenamento como segue:

CUSTO DE ARMAZENAMENTO (CA) = (CUSTO OPERACIONAL x Q) + CAE

sendo:

Custo operacional $=\mathrm{R} \$ 3,30 / \mathrm{t}$ ano.

CAE $=$ Custo anual equivalente do investimento $=\mathrm{R} \$ 335.066,00$ a.a.

$\mathrm{Q}=$ Quantidade armazenada em toneladas.

Ambos os custos, de transporte e de armazenagem, foram calculados utilizando a capacidade de giro como parâmetro comum.

A capacidade de giro é a relação entre a quantidade (em t) de grãos recebidos e a capacidade estática (em t) disponível. Então:

Giro $=\underline{\text { Recebimento }}$

Capacidade

Por exemplo, para um recebimento de 100.000 t e um armazém com capacidade de $42.000 \mathrm{t}$, teremos um giro de 2,38. Para um recebimento de 100.000 t e uma capacidade de $100.000 \mathrm{t}$, teremos um giro de 1,00. E, para um recebimento de 100.000 t e nenhuma capacidade estática, teremos giro zero. 
Desta maneira, a capacidade de giro é o parâmetro comum para cálculos dos custos logísticos para diferentes quantidades comercializadas. As quantidades comercializadas testadas neste modelo foram: $100 \mathrm{mil} \mathrm{t,} 200 \mathrm{mil} \mathrm{t,} 300 \mathrm{mil} \mathrm{t,} 400$ mil t, 500 mil t, 600 mil t e 700 mil t. Com estes dados pôde-se traçar o comportamento dos custos logísticos.

Para minimização dos custos deve-se fazer um balanceamento entre os custos dos componentes logísticos; portanto o custo logístico é a soma dos custos de transportes e dos custos de armazenagem, ou seja

CUSTO LOGÍSTICO = CT + CA

Em que:

$\mathrm{CT}=$ Custos de transportes

CA = Custos de armazenamento

Pelo conceito de compensação de custos, o maior custo de transporte pode ser compensado pelo menor custo de armazenagem e vice-versa. O importante é localizar o ponto mínimo da curva de custo logístico, que situa a combinação de transporte e capacidade estática disponível que minimiza os custos.

\section{Viabilidade dos Investimentos em Armazenagem nas Propriedades}

Também foi realizada avaliação e análise da viabilidade de investir na implantação de armazém secador, especificamente para uma propriedade rural localizada na região oeste paranaense, com área total de 317 hectares e que se dedica à produção de soja, milho e trigo.

As médias de área plantada e de produção de soja e de milho da propriedade analisada referentes às últimas três safras encontram-se na Tabela 1.

Tabela 1: Área Plantada e Produção de Soja e de Milho da Propriedade Analisada

\begin{tabular}{lcc}
\hline CULTURA & ÁREA (HA) & PRODUÇ̃̃O (SACAS) \\
\hline SOJA & 217 & 13.000 \\
MILHO & 109 & 16.000 \\
\hline
\end{tabular}

Fonte: dados da pesquisa.

A infra-estrutura de armazenagem refere-se a um conjunto, com secador completo de grãos, composto pelas seguintes unidades: 
. Um secador com capacidade para secagem de 20 t/hora.

. Um silo com capacidade de armazenar 15.000 sacas para milho.

. Um silo com capacidade para armazenar 15.000 sacas para soja.

A instalação do armazém será feita na propriedade, em área destinada atualmente para o plantio de culturas anuais, sendo necessários 0,5 hectares de terra.

Tabela 2: Valores para a Implantação de Infra-estrutura de Armazenagem na Propriedade

\begin{tabular}{llr}
\hline ITEM & \multicolumn{1}{c}{ ESPECIFICAÇÃO } & $\begin{array}{r}\text { VALOR } \\
\text { (em R\$) }\end{array}$ \\
\hline Terreno & 0,5 há (custo de oportunidade ano) & 665,00 \\
\hline Construções & Estrutura p/ moega, secador e silos & $90.000,00$ \\
\hline Obras complementares & Rede de elétrica & $20.000,00$ \\
\hline Máquinas e equipamentos & 01 secador 20t/hora & $56.499,89$ \\
& 01 fornalha p/ sec. 20t/hora & $15.494,53$ \\
& 01 máquina de pré-limpeza 20t/hora & $17.144,59$ \\
& 01 elevador de moega 30t/hora & $9.825,52$ \\
& 01elevador de carga p/ sec. 40t/hora & $12.020,41$ \\
& 01elevador de carga p/ silos 40t/hora & $12.712,04$ \\
& 01 silo 15.000 sacas (soja) & $50.679,15$ \\
& 01 silo 15.000 sacas (milho) & $50.679,15$ \\
& 01 rosca de descarga silo (soja) & $6.522,93$ \\
& 01 rosca de descarga silo (milho) & $6.522,93$ \\
\hline Instalação, montagem em & Transporte de equipamentos & $7.202,16$ \\
Testes & Montagem & $29.812,99$ \\
& Canalização & $17.367,08$ \\
\hline IPI & Seguro de montagem & $1.554,26$ \\
\hline Capacitação & Máquinas e equipamentos & $13.273,41$ \\
\hline Projeto & Treinamento p/ operador & 400,00 \\
\hline & Projeto viabilidade econômica (0,5\%) & $2.091,88$ \\
\hline
\end{tabular}

Fonte: dados da pesquisa.

Como os serviços de secagem e armazenagem não influenciarão, de maneira significativa, na quantidade produzida, considerando ainda que os produtos soja e milho se inserem no mercado que mais se aproxima da concorrência perfeita; portanto o produtor isoladamente não tem influência na determinação dos preços; a análise da viabilidade da implantação do armazém secador na propriedade foi feita levando-se em conta a possibilidade de se obterem ganhos com redução de custos e melhor qualidade final do produto, a partir dos seguintes pontos:

. Possibilidade de escolha da melhor época para comercialização.

. Aproveitamento total do produto (resíduos, mais grão quebrados). 
. Flexibilidade no escoamento da produção em época de pico de colheita, proporcionando redução nos gastos com fretes.

. Diminuição de perdas com descontos e classificação, eliminando ainda o pagamento de taxa de secagem.

- Adequação da colheita dentro do período que garanta a melhor qualidade do produto, pois o produtor terá flexibilidade para seguir as recomendações quanto ao grau de umidade ideal do produto a ser colhido.

Com base nas características do investimento, a Tabela 2 explicita os valores e respectivas aplicações para a infra-estrutura de armazenagem na propriedade; a Tabela 3 demonstra os valores referentes aos custos, economias e resultados proporcionados pela armazenagem. Consideraram-se, para efeito de viabilização do investimento, recursos captados junto ao FINAME $(\mathrm{R} \$ 300.000,00)$ e ao PROAZEM (R\$108.421,13), ambos com taxa de juro de 8,75\% ao ano.

\section{Tabela 3: Valores Referentes aos Custos, Economias e Resultados Proporcionados pela Armazenagem}

\begin{tabular}{llr}
\hline ITEM & ESPECIFICAÇÃOO & $\begin{array}{r}\text { VALOR } \\
\text { (em R\$) }\end{array}$ \\
\hline DEPRECIAÇÃO & $\begin{array}{l}\text { Equipamentos e instalações } \\
\text { (ano) }\end{array}$ & $\mathbf{2 7 . 8 9 1 , 7 3}$ \\
\hline CUSTOS OPERACIONAIS & & \\
Mão-de-obra & & \\
Serviços & Energia elétrica & $3.840,00$ \\
Manutenção, reparos, limpeza & & $1.800,00$ \\
Seguro & Instalações e conteúdo & $1.650,00$ \\
Lenha & \multicolumn{1}{c}{ Total dos custos operacionais } & $5.000,00$ \\
& Milho & $2.638,00$ \\
RECEITAS & Soja & $\mathbf{1 4 . 9 2 8 , 0 0}$ \\
Ganhos de Comercialização & Milho & $22.500,00$ \\
& Soja & $32.500,00$ \\
\hline Redução de custos com secagem & Milho & $10.500,00$ \\
& Soja & $13.050,00$ \\
\hline Redução de custos com frete & Milho & $13.174,00$ \\
& Soja & $7.200,00$ \\
\hline Ganhos de qualidade & Resíduos de milho & $5.000,00$ \\
& Resíduos de soja & $6.000,00$ \\
\hline Ganhos c /sobras & & $1.125,00$ \\
& & $2.250,00$ \\
\hline & Receitas & $\mathbf{1 1 3 . 2 9 9 , 0 0}$ \\
\hline LUCRO ANUAL & Custos operacionais & $113.299,00$ \\
& Saldo (Receitas - Custos operacionais) & $(14.928,00)$ \\
& $\mathbf{9 8 . 3 7 1 , 0 0}$ \\
\hline
\end{tabular}

Fonte: dados da pesquisa. 
Para mensurar a viabilidade financeira do investimento, considerou-se uma TMAR igual a $15 \%$ ao ano.

\section{Resultados}

Os resultados obtidos neste estudo estão evidenciados por meio das Figuras de 3 a 5, que mostram o comportamento dos custos de transporte, custos de armazenagem e custos logísticos, de acordo com a análise de sensibilidade para as quantidades de grãos testadas, além da aferição da viabilidade do investimento em armazenagem na propriedade. Uma vez que o comportamento entre as diversas capacidades de armazenagem foi semelhante, apenas reproduz-se em gráficos algumas situações (100 mil, 400 mil e 700 mil t).

\section{Custos de Transportes}

Foi realizada uma avaliação sobre o histórico de fretes da região Oeste do Paraná, para identificar a sazonalidade. Os resultados obtidos mostraram que $\mathrm{F}_{\mathrm{s}}$ (Preço unitário médio do frete na safra em $\mathrm{R} \$ / \mathrm{t}$ ) e $\mathrm{F}_{\mathrm{e}}$ (Preço unitário médio do frete na entressafra em $\mathrm{R} \$ / \mathrm{t})$, são, respectivamente, $\mathrm{R} \$ 55,19$ e $\mathrm{R} \$ 38,50$.

$\mathrm{Q}_{\mathrm{s}}$ e $\mathrm{Q}_{\mathrm{e}}$ representam as quantidades de grãos recebidas; serão demonstradas em cada gráfico, iniciando pelo que segue, que demonstra uma quantidade de recebimento de grãos de 100.000 t.

Quando se considera capacidade de giro, considera-se a quantidade recebida de grãos em relação à capacidade armazenadora; portanto quanto menor o giro, maior é a capacidade armazenadora; à medida que o giro vai aumentando, a capacidade estática vai diminuindo.

Pelos resultados, pode-se observar que à medida que a capacidade de giro aumenta, os custos de transporte também aumentam. Isso ocorre porque a parcela da produção que não teve como ser armazenada é maior, e terá que ser transportada ao porto com fretes a preço de safra.

A capacidade de giro que melhor minimiza os custos de transporte é a área ao redor de 1 . Tanto para 100 mil t quanto para 700 mil t, há uma tendência semelhante. Com capacidade de giro zero, ou seja, nenhum armazém, o custo de transporte é máximo, pois toda a produção deverá ser escoada com fretes a preço de safra. O giro 1 ou qualquer giro menor que 1, apresenta o mesmo custo 
de transporte, pois não importa a capacidade estática ser maior ou igual ao recebimento, a quantidade a ser transportada será apenas a recebida. Para giro maior que 1, o custo do transporte só tende a aumentar. Este resultado está mostrando o comportamento óbvio do menor custo de transporte fora da safra, quando os fretes são menores; porém esta análise deve ter valor apenas inserida nos custos logísticos.

\section{Custos de Armazenagem}

Ao contrário dos custos de transportes, os custos com armazenagem têm comportamento em direção máximo. Pelos resultados, observou-se comportamento semelhante para todas as quantidades testadas. Quanto menor a capacidade de giro, maior tende a ser o custo de armazenamento. $\mathrm{O}$ ponto que minimiza custos de armazenagem é aquele representado pela maior capacidade de giro. Isso porque, neste ponto, há investimento em apenas um armazém de 42.000 t. Porém se sabe que o maior giro é o que representa o custo de transporte máximo; portanto, para definir o ponto que minimiza os custos, é necessário fazer um balanceamento entre os custos logísticos, ou seja, uma compensação entre os custos de transporte e de armazenagem.

\section{Custos Logísticos}

Pela compensação de custos logísticos, é possível encontrar o ponto mínimo da curva de custo logístico, que demonstra qual a capacidade de giro que melhor minimiza custos.

As figuras a seguir mostram as curvas de Custos de Transportes e Custos de Armazenagem. Também mostra a curva de Custos Logístico e sua tendência para cada uma das quantidades de grãos testadas, podendo-se definir o ponto mínimo da curva de custo logístico.

Para todas as quantidades de grãos testadas observou-se a mesma tendência e o mesmo comportamento.

O giro zero, onde não há armazéns, é o ponto de maior custo logístico, porquanto, apesar de não haver nenhum investimento em armazenagem, o custo de transporte é máximo.

A partir do giro 1, e conforme este aumenta, o custo logístico tende a aumentar também. Isso se dá porque o número de armazéns diminui, decrescendo o custo de armazenagem, mas aumentando o custo de transporte, particularmente na safra. 
O custo logístico mínimo está localizado na área de capacidade de giro 1 . Neste ponto o custo de transporte é mínimo e o custo de armazenagem possui tendência decrescente.

Assim, identificou-se como principal direcionador dos custos logísticos da comercialização da safra, nos parâmetros analisados, como sendo os custos de transporte.

Figura 3: Curvas de Custos de Transporte, Custos de Armazenagem e de Custo Logístico para 100.000 Toneladas

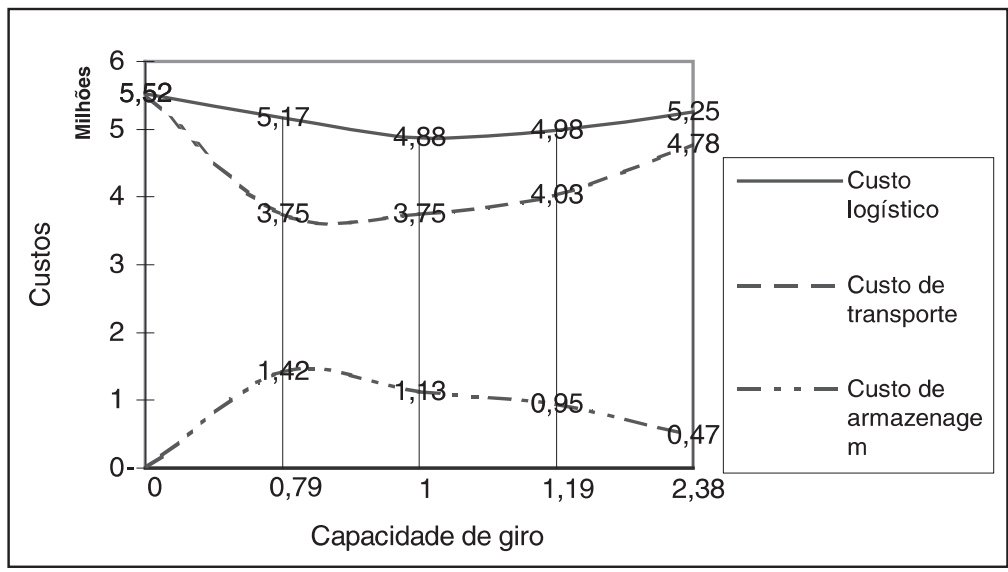

Fonte: dados da pesquisa.

Figura 4: Curvas de Custos de Transporte, Custos de Armazenagem e de Custo Logístico para 400.000 toneladas

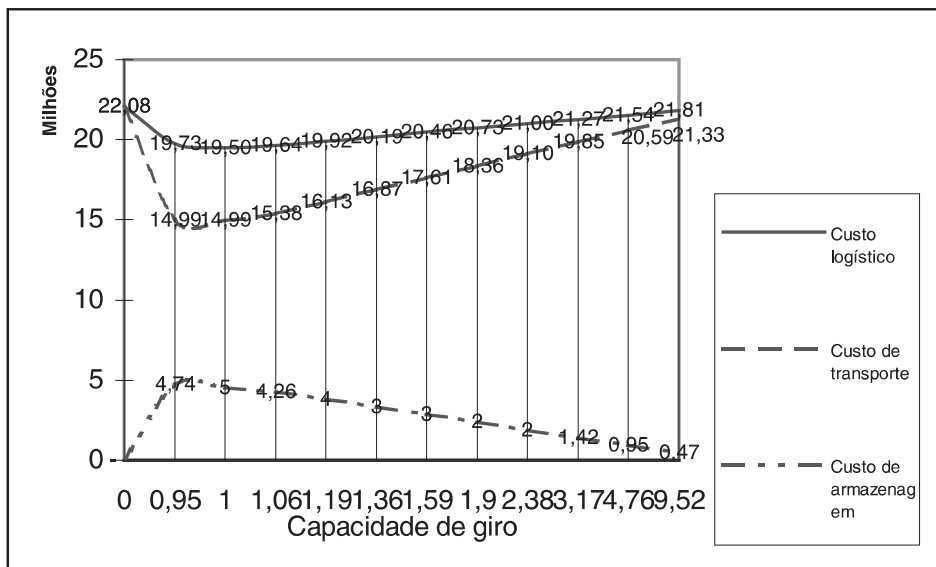

Fonte: dados da pesquisa. 
Figura 5: Curvas de Custos de Transporte, Custos de Armazenagem e de Custo Logístico para 700.000 Toneladas

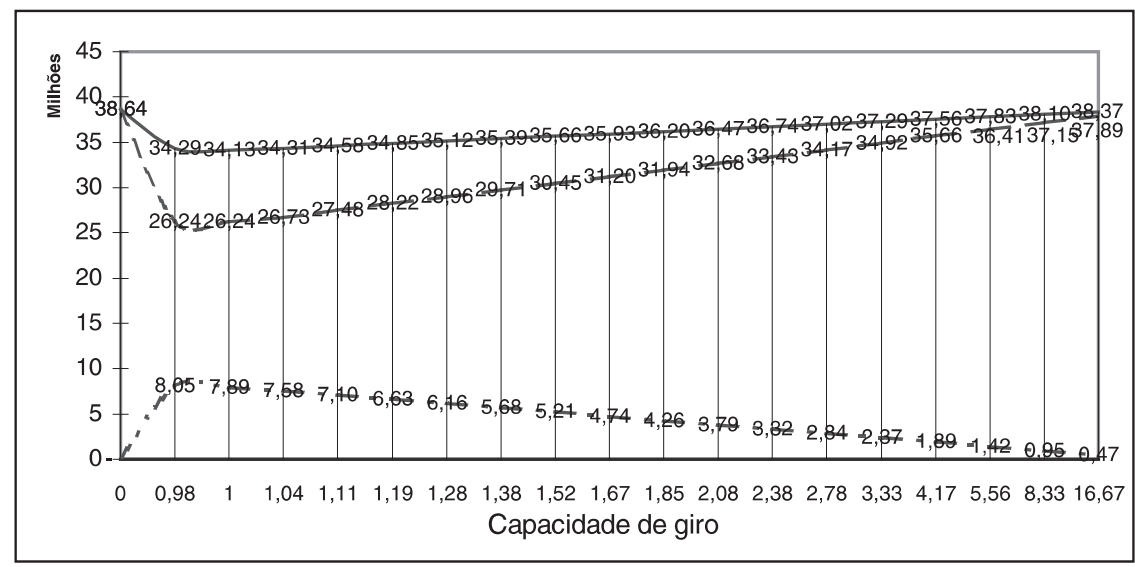

Fonte: dados da pesquisa.

\section{Viabilidade dos Investimentos nas Propriedades}

Por meio do fluxo de caixa do período e TMAR de 15\% ao ano, considerandose a incidência de alíquota de imposto de renda de 5\%, obteve-se o Valor Presente Líquido positivo, o que significa que o projeto é capaz de gerar benefícios suficientes para recuperar o valor investido R \$ 420.467,92 e obter um excedente de R \$ 45.703,33. A análise de sensibilidade deste resultado encontra-se na Figura 6.

Figura 6: Sensibilidade do VPL a TMAR

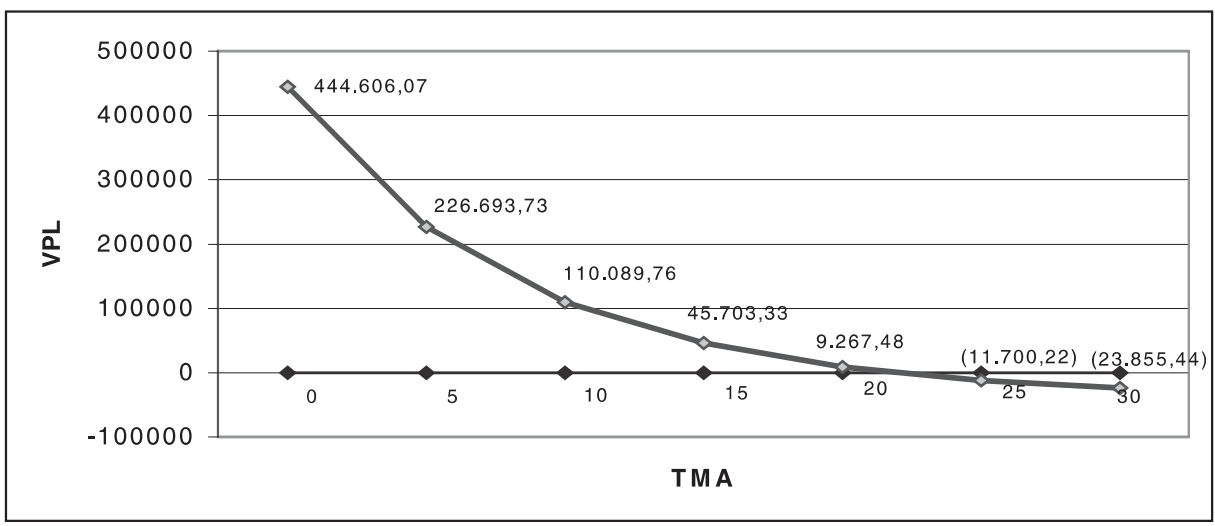

Fonte: resultados da pesquisa.

A TIR (Taxa Interna de Retorno) obtida foi de 21,88\%, confirmando a viabilidade do investimento. 


\section{Conclusão}

Este estudo objetivou avaliar os custos logísticos da comercialização da soja no Brasil, a partir das preocupações da escassez de estruturas de armazenagem e da imposição da comercialização da safra rapidamente pelo produtor. Nessas condições, o estudo valeu-se de informações dos fretes diferenciados nos períodos de safra e entressafra, para rotas entre a região oeste paranaense e o Porto de Paranaguá (PR).

O princípio teórico em que se baseou a análise está na logística empresarial, mais especificamente nos seus princípios de compensação de custos. A idéia é a de que a decisão estratégica empresarial deve pautar-se pelo somatório dos custos logísticos, visando a identificar sua área de mínimos custos totais das operações. Dentro da visão, pode-se tomar uma decisão acertada de operação, mesmo contando com uma ou mais atividades logísticas fora de seu ponto de mínimo.

Nesse sentido, foi possível comprovar a eficiência dos investimentos em estruturas de armazenagem, o que é demonstrado pelos gráficos que representam os custos logísticos totais.

Ao redor da capacidade de giro 1, foi identificado o menor custo logístico total, ou seja, este é o ponto que minimiza custos. Isso ocorre porque os investimentos em armazenagem são muito elevados, obtendo uma capacidade estática com capacidade para armazenar toda a produção. Logo, os custos com armazenagem neste ponto são altos, porém os custos com transportes são mínimos, pois toda a produção poderá ser transportada durante a entressafra, quando os fretes são baixos.

Com maiores possibilidades de não vender a safra no momento de custos de transportes elevados, o custo logístico anual é menor, sendo tanto menor quanto mais esta capacidade se aproximar da unidade. Isto equivale a dizer que o investimento é viabilizado pela remuneração de seus custos operacionais e pelas economias de fretes.

Neste caso, ficou destacado o custo de transporte como direcionador dos custos logístico setoriais; porém, à medida que novas alternativas modais sejam disponibilizadas, novos estudos devem ser elaborados, assim como os fretes também devem ser entendidos como diferenciados entre os corredores de transporte, o que também implica estudos específicos, ou seja, as situações específicas determinam as próprias situações otimizadas, implicando a necessidade de permanente atualização e regionalização desta análise. 
Por outro lado, no nível das propriedades, também ficou comprovada a viabilidade do investimento.

Estes resultados podem,em princípio, sugerir que a análise também cabe para outros agronegócios, principalmente naqueles que se caracterizam pela sazonalidade, tanto da matéria prima, quanto do produto acabado, considerandose que se lida, nestes negócios, regularmente com o problema da concentração da produção primária e pulverização do consumo. Nestes casos, comercializar na safra pode implicar perdas econômicas potenciais, identificadas no estudo.

Embora este trabalho haja investigado as estratégias, considerando-se informações de uma região paranaense, o que não deixa de ser uma limitação típica de estudo de caso, os resultados sugerem que outras regiões e outros agronegócios deveriam ser investigados para se ter melhor dimensão das perdas proporcionadas pelas carências na capacidade de armazenagem, o que pode ter implicações muito significativas quanto à renda dos agentes do agronegócio brasileiro.

\section{Artigo recebido em 07.05.2003. Aprovado em 07.05.2004.}

\section{ReferênCias Bibliográficas}

ALVES, M. R. P.A.

Logística agroindustrial. In: BATALHA, M. O. Gestão Agroindustrial. São Paulo: Atlas, 1997. v. 1, cap. 4.

ARAÚJO, M. P.;

MARTINS, R. S.

Logística de transporte de cargas do agronegócio brasileiro: evidências para uma interpretação à luz da teoria dos custos de transação. (compact disc). In: CONGRESSO BRASILEIRO DE ECONOMIA E SOCIOLOGIA RURAL, 55., 2002, Passo Fundo.

Anais.... Brasília, Sober, 2002.
BALLOU, R. H.

Logística empresarial: transportes, administração de materiais e distribuição física. São Paulo: Atlas, 1993.

\section{BAYLISS, B.}

Transport policy and planning: an integrated analytical approach. Washington: The World Bank, 1996. $68 \mathrm{p}$.

BEILOCK, R. et al.

Road conditions, border crossing and freight rates in Europe and Western Asia. Transportation Quarterly, v. 50, n. 1, p. 79-90, Winter 1996. 
CAIXETA-FILHO, J. V.

Sistema de informações de fretes para cargas agrícolas: concepção e aplicações. In: CAIXETA-FILHO, J. V.; GAMEIRO, A. H. (Orgs.) Sistemas de gerenciamento de transportes: modelagem matemática. São Paulo: Atlas, 2001. cap. 2.

Sistema de transporte e logística: conceitos básicos e modelagem matemática. In: ZYLBERSZTAJN, D.; NEVES, M. F. (Orgs.) Economia e gestão dos negócios agroalimentares. São Paulo: Pioneira, 2000. cap. 2.

CAIXETA-FILHO, J. V. et al..

Competitividade no agribusiness: a questão do transporte em um contexto logístico. In: FARINA, E. M. Q.; ZYLBERSZTAJN, D. (Orgs.) Competitividade no agribusiness brasileiro. 1998. CO (compact disc) CD São Paulo: FEA/FIA/Pensa/USP.

Movimentação rodoviária de produtos agrícolas selecionados. In: CAIXETA-FILHO, J. V.; GAMEIRO, A. H. (Orgs.) Transporte e logística em sistemas agoindustriais. São Paulo: Atlas, 2001. cap. 4.

COASE, R. H.

The nature of the firm. Economica, $n$. 4. 386-405p. 1937.

\section{CONFEDERAÇÃO NACIONAL DOS TRANSPORTES.}

Diagnóstico do transporte de cargas. Brasília: Confederação Nacional dos Transportes/Centro de Estudos em Logística da Universidade Federal do Rio de Janeiro, 2002.

\section{CORREAJÚNIOR, G.}

Principais determinantes de preço do frete rodoviário para o transporte de soja em grãos em diferentes Estados brasileiros: uma análise econométrica. 2001. 83 f. Dissertação (Mestrado em Economia Aplicada) Universidade de São Paulo - USP, São Paulo.

\section{CORREAJÚNIOR, G. et al.}

Oferta de transportes: fatores determinantes do valor do frete e o caso das centrais de carga. In: CAIXETAFILHO, J. V.; MARTINS, R. S. (Orgs.) Gestão logística do transporte de cargas. São Paulo: Atlas, 2001. cap. 4.

\section{COSTA, N. et. al.}

O Impacto do pedágio no transporte de grãos no Paraná. Curitiba: OCEPAR, 2002.

HUMMEL, P.R.V.; TASCHNER, M.R.R.

Análise e decisão sobre investimento e financiamentos. São Paulo: Editora Atlas, 1995.

\section{LIMA, M. P.}

Custos logísticos - uma visão gerencial, Rio de Janeiro: Centro de Estudos em Logística da Universidade Federal do Rio de Janeiro. 1998. Disponível em: <http:// www.cel.coppead.ufrj.br>. Acesso em: 06 Abril 2003

Os custos de armazenagem na logística moderna, Rio de Janeiro: Centro de Estudos em Logística da Universidade Federal do Rio de Janeiro. 1998. Disponível em: <http:// www.cel.coppead.ufrj.br>. Acesso em: 06 Abril 2003 
MARTINS, R. S.;

ARAÚJO, M. P.;

SALVADOR, E. L.

Fretes e coordenação entre os agentes no transporte rodoviário: o caso do complexo soja paranaense. I Encontro de Economia Paranaense, Maringá, 2002. CD-ROM.

Logística do transporte rodoviário do complexo soja no estado do Paraná In: CONGRESSO BRASILEIRO DE ECONOMIAESOCIOLOGIARURAL, $55^{\circ}$ 2002. CD (compact Disc). Passo Fundo. Anais ... Brasília, Sober, 2002.

PARANÁ (Estado).

Secretaria dos Transportes. Transporte e escoamento das safras agrícolas através do complexo de Paranaguá. Curitiba: SETR/PR, 2001.

\section{SIFRECA.}

Sistema de Fretes para Cargas Agrícolas. Disponível em: <http:// www.sifreca.esalq.usp.br>. Acesso em:

SOARES, M. G.;

GALVANI, P. R. C.;

CAIXETA-FILHO, J. V.

Transporte de soja em grãos e farelo de soja no Brasil. Piracicaba, Preços

Agrícolas, v. 11, nº 126, abr. 1997.

WILLIANSOM, O. E.

Las instituciones económicas del capitalismo. México: Fondo de Cultura Económica, 1989. 435 p. 